\title{
COMO SE "VESTIA" O VINHO DO PORTO (SÉCULOS XVI E XVIII)
}

\author{
António Barros CARDOSO \\ CITCEM, Faculdade de Letras da Universidade do Porto \\ abarroscardoso@sapo.pt
}

\section{Resumo}

Este artigo pretende traçar, à luz dos conhecimentos atuais, a evolução das formas usadas para armazenar o vinho do Porto durante os séculos XVI a XVIII, e focar da importância da arte da tanoaria na cidade do Porto, enquanto primeira arte de "vestir o vinho". Depois o vidro substituiu a madeira no armazenamento do vinho do Porto para algumas finalidades ou complementa-a no processo de guarda e envelhecimento. Por exemplo, os "Vintage Port" não dispensam o envelhecimento em garrafa de vidro e a evolução da tecnologia do tratamento do mesmo está intimamente ligada ao formato da garrafa cilíndrica, a única que permite acomodar nas garrafeiras, em pilha, os vinhos que, após estágio de um ano em madeira, continuam o seu processo de envelhecimento na própria garrafa.

Palavras-chave: Porto, Vinho do Porto, garrafas, tanoaria

\section{Abstract}

This article intends to trace, in the light of current knowledge, the evolution of the forms used to store Port wine during the 16th and 18th centuries, and to focus on the importance of the art of cooperage in the city of Porto, as the first art of "dressing the wine ". Then the glass botle replaced the wood in the storage of Port Wine for some purposes or complements it in the process of guarding and aging. For example, "Vintage Port" cannot be obtained without aging in glass bottles and the evolution of glass treatment technology is therefore closely linked to the shape of the cylindrical bottle, the only one that allows to accommodate in the wineries the wines that after remaining a year in wood, continue your aging process in the bottle itself.

Key words: Port, Port wine, bottles, cooperage

\section{Introdução}

Não se encontram em grande número estudos históricos sobre as formas de guardar o vinho do Porto. Propomo-nos no entanto deixar aqui algumas notas que nos parecem importantes sobre a temática em apreço. Quando falamos de "vestimenta" do vinho queremos significar vasilhame que cobre e guarda o precioso líquido a que nos reportamos - o Porto. Fazemos esta ressalva para que a 
expressão "vestimenta" não seja confundida com a rotulagem das garrafas ou de outros invólucros onde se guarda o vinho.

Ao contrário do que acontece por exemplo na região de Bordéus, os vinhos do Porto, sabemolo, só tomaram o nome Porto porque armazenados e preparados para exportação junto à barra que Ihe servia de porta para o mundo e dela saíam - a barra do Douro junto ao Porto. Tais vinhos são produzidos numa região montanhosa ligada à cidade do Porto pelo rio Douro, um curso de água hoje tranquilo por força das muitas barragens construídas ao longo do seu curso mas que, noutros tempos foi um rio difícil de navegar. Contudo, desde tempos medievais que o vinho produzido em "cima do Douro" foi transportado em pipas, dispostas da forma mais conveniente em barcos rabelos, de uma configuração própria para vencer as agruras do rio.

\section{Vila Nova a par de Gaia - Guardiã do Vinho do Porto}

Até aos anos quarenta do século XVIII, o vinho resultante das uvas das vindimas anuais durienses era conduzido até à cidade do Porto e, até ao mês de Março/Abril do ano seguinte ao da colheita, era guardado nos armazéns dentro do espaço urbano que hoje conhecemos como Porto. Tais vinhos não permaneciam aí muito tempo, seguindo diretamente para os portos de importação, particularmente para as docas da llha inglesa de Guernesey e para os cais de Londres e de outros portos britânicos ou rumavam aos portos coloniais portugueses, com destaque para os das capitanias do Brasil. O estanciar dos vinhos ocorria nestes portos de destino. Contudo, por razões que se prendem com a falta de qualidade de alguns carregamentos, os destinatários importadores e respetivos comissários de comerciantes ingleses do Porto, começaram por essa altura a comprar somente vinhos que "tivessem dado a prova do tempo". Ou seja, vinhos que tivessem permanecido nos armazéns do Porto, pelo menos durante três anos. Ora, está bem de ver que tais armazéns que até aquela data se concentravam no velho casco urbano, ainda cercado pelos muros da cidade, mostraram-se insuficientes para guardar o triplo da quantidade de vinhos relativamente à sua capacidade de armazenagem. É nessa altura que os vinhos do Douro começam a ser armazenados na margem do rio fronteira ao Porto. Nasciam as caves do Vinho do Porto em Vila Nova de Gaia (LIMA, Eng. J. da Costa, 1945, I).

\section{Os tanoeiros}

A mudança na forma de tratar os vinhos do Douro fomentou a multiplicação de armazéns em Vila Nova de Gaia, embora não tenha sido, de per si, responsável pelo aperfeiçoamento da arte da tanoaria no Porto, para isso contribuiu decisivamente. De facto, a tanoaria como arte primeira no que se refere à confeção do vasilhame para a guarda dos vinhos e outros líquidos tem tradição antiga na cidade do Porto. Pelo menos desde Maio de 1443 que os tanoeiros são notícia nos livros da Câmara da Cidade do Porto. Com efeito, no dia 25 desse mês e ano foi nomeado João Fernandes para exercer o cargo de Vedor do Ofício, competindo-Ihe repartir a matéria-prima (aduela e vimes) pelos 
oficiais tanoeiros. Compreende-se já nesse tempo recuado a importância do ofício para a economia da urbe uma vez que que se recomenda, sob penas, que os tanoeiros nunca se ausentassem da cidade (CRUZ, António, 1943, p. LXVI).

Ao tempo de D. Afonso V, uma ata de vereação de 28 de Agosto de 1475 dá nota da presença deste grupo sócio profissional entre os principais mesteirais da cidade. Nessa altura, como olheiros, vigiavam as decisões do governo municipal. Representaram então o ofício da tanoaria Vasco Annes e Gill Fernandez (CRUZ, António, 1943, p. XXX).

Anos mais tarde, na vereação de 3 de Julho de 1484, os tanoeiros do Porto voltaram a dar sinais da sua importância, quando elegem Pedro Álvares, morador ao Postigo, para o cargo de marcador de todas as obras ou louças feitas pelos tanoeiros da urbe. Proibiu-se então a venda de qualquer obra de tanoaria sem as marcas da cidade e do seu fabricante. Visava-se evitar as fraudes no fabrico do vasilhame, vulgares na arte da tanoaria. De resto, é também esta a data da instituição do primeiro livro de registo de marcas na cidade do Porto e foram precisamente os tanoeiros os primeiros oficiais mecânicos a imprimir nesse livro as respetivas marcas. Contava então o Porto com mestres de tanoaria (CRUZ, António, 1943, p. XXX).

Entrado o século $\mathrm{XVI}$, contavam-se entre as propriedades prediais municipais 7 assentos de aduelas, todos eles localizados na Rua dos Banhos. Pagavam então à cidade um foro que variava entre 20 e 25 reais. Aqui os tanoeiros recorriam à força do fogo para dar à madeira a curvatura adequada para a construção das pipas e toneis (MACAHDO, Maria de Fátima Pereira, 1997, p. 109).

Torna-se por isso seguro afirmar que, desde os tempos medievos, esta arte ganhou importância na cidade do Porto. Produziam-se então aqui tonéis, meios tonéis, cubas, pipos de meio tonel e redondeletas de quarto de tonel (GUIMARÃES, Gonçalves, 1998, p. 5).

\section{-Tanoeiros comerciantes de vinhos na cidade}

Muitos destes oficiais do ofício da tanoaria foram também comerciantes de vinho no Porto, atividade documentada pelos mesmos desde finais do século XVI (SILVA, Francisco Ribeiro da, 1988, Vol. I, p. 114-115) ${ }^{1}$. De facto, numa lista dos mais importantes mercadores de vinho elaborada com base nos livros da Imposição do Vinho respeitantes aos anos de 1620 a 1640, constam já 4 tanoeiros, alguns já com expressão significativa no negócio vinícola (SILVA, Francisco Ribeiro da, 1988, Vol. I, p. 156-160), sinal claro da importância do ofício na época, mas também da existência de uma certa tendência por parte dos tanoeiros do Porto para se envolveram no comércio dos vinhos que preenchia o vácuo do vasilhame que fabricavam.

Não se estranha pois que, chegados ao século XVIII, a participação dos tanoeiros portuenses no trato vinícola se mostre a acompanhar o desenvolvimento do sector vitivinícola na vida económica da cidade. A arte da tanoaria conhece e desenvolve novos métodos graças à atividade dos ingleses, os principais interessados no seu incremento. Embora se desconheçam os contornos técnicos de tal evolução, a verdade é que, desde 1708, um alvará régio autorizou os ingleses do Porto a terem

\footnotetext{
${ }^{1}$ Nos anos de 1584, 1585, 1591 e 1639, constam a manifestar açúcar na Alfândega portuense pelo menos 3 tanoeiros.
} 
oficiais tanoeiros ao seu exclusivo serviço nos seus armazéns, casas e feitorias, sem que fossem obrigados a fazer o exame do ofício, a fim de lhes fabricarem as pipas que transportavam os seus vinhos para fora (CARDOSO, António Barros, 2003, Vol. I, p. 538).

Com base nas moradas dos registos da Imposição do Vinho foi possível conhecer as áreas da cidade do Porto e Vila Nova onde se localizaram as tanoarias entre (1700 e 1756) constam do mapa seguinte:

Pode comprovar-se através da análise do mapa que as áreas envolventes da Porta Nova, as áreas ribeirinhas de Miragaia e de Vila Nova, são áreas de referência na fixação dos tanoeiros. Foram 41 os mestres tanoeiros que se envolveram no negócio dos vinhos entre 1700 e 1756 (CARDOSO, António Barros - Baco \& Hermes, 2003, Vol. I, p. 538). Muitos deles apenas manifestaram vinhos esporadicamente na Imposição do Porto. Significa isto que não ancoravam grandes cabedais no negócio ou que o fizeram à comissão, em nome de terceiros. Porém alguns deles assumem-se mesmo como grandes mercadores de vinho.

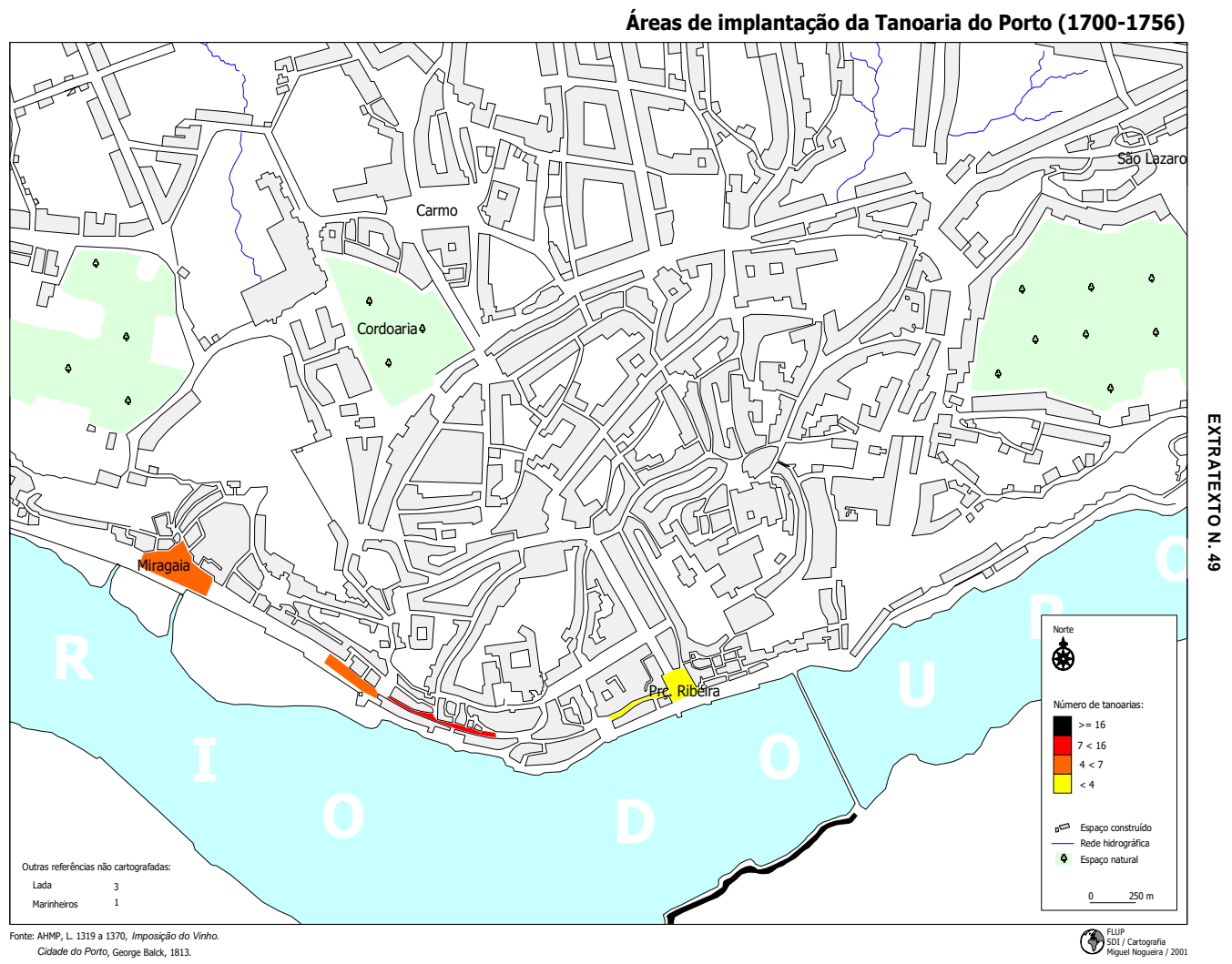

Figura 1- (Fonte: AHMP - Livros da Imposição do Vinho 1700-1756 )

Ao longo do período cronológico que estudamos de forma mais minuciosa, as fontes indicamnos que foi irregular a presença dos tanoeiros no mercado portuense de vinhos (CARDOSO, António Barros - Baco \& Hermes, 2003, Vol. I, p. 537): 


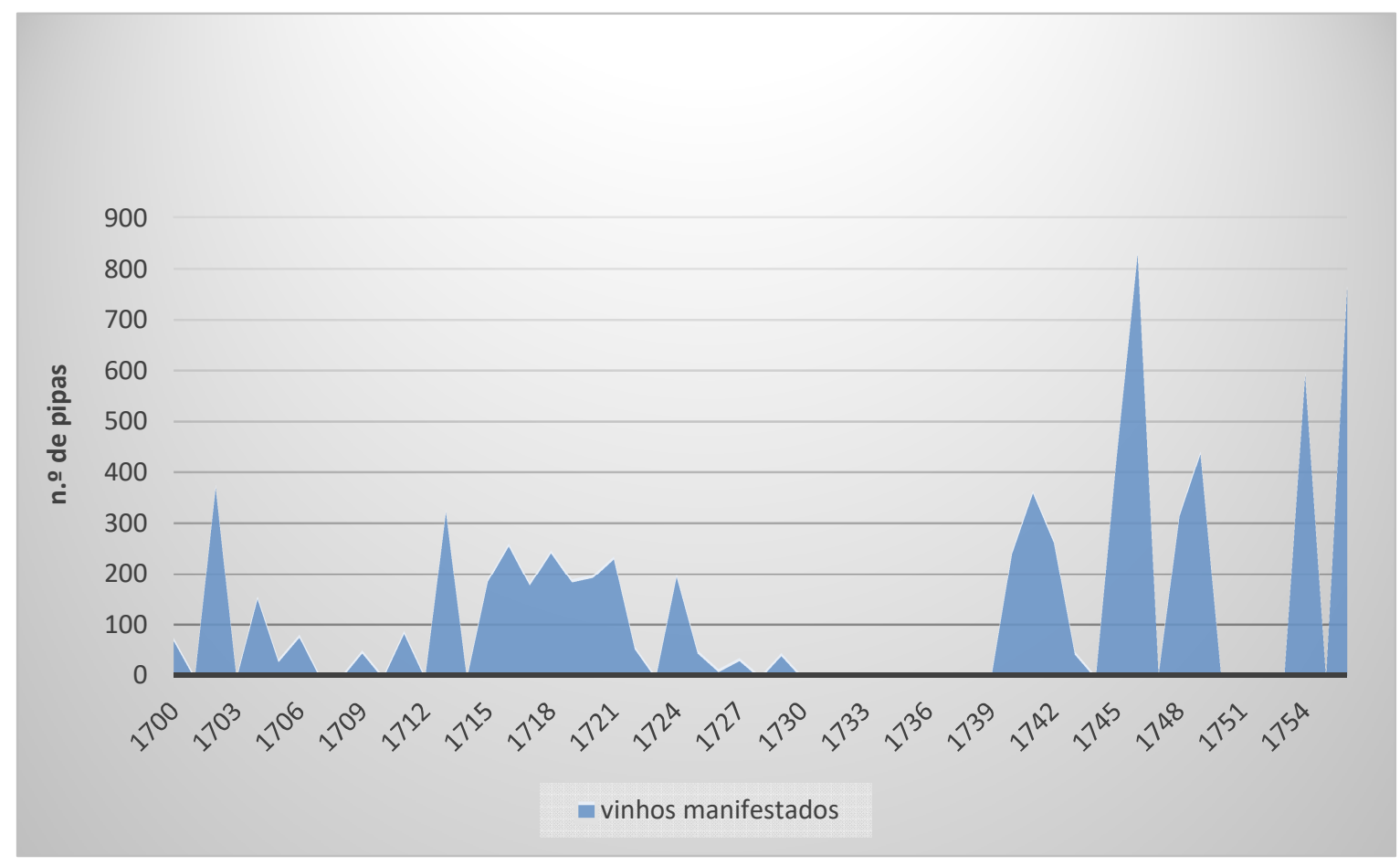

Figura 2- Vinhos manifestados na Imposição do Porto por tanoeiros (1700-1756). Fonte: AHMP - Livros da Imposição do Vinho 1700-1756

Pelo gráfico percebe-se que, desde os inícios do século e até 1715 , os volumes de vinho que movimentaram não foram muito expressivos. Entre 1716 e 1724 apresentaram-se regularmente na Imposição portuense. De 1724 a 1730 os volumes de pipas manifestados descem claramente e há mesmo um longo período de ausência do negócio vinícola por parte dos tanoeiros do Porto, ao longo de toda a década de 30 . A partir de 1740, os seus manifestos voltam a aumentar de volume e de frequência anual. Ou seja, o seu envolvimento no negócio vinícola seguiu o desenvolvimento do sector a partir de 1715 mas somente até ao ponto em que os mercadores britânicos começaram a dominar totalmente o comércio de vinhos no Porto, o que acontece de forma mais intensa entre 1724 e 1738. A partir de 1740, altura em que o crescimento do sector conhece algum refreamento e em que o dinamismo dos ingleses entra numa fase de estabilização, novas oportunidades de negócio com os vinhos no Porto ficaram reservadas aos tanoeiros que daí até 1756 (data da criação da Companhia Geral da Agricultura das Vinhas do Alto-Douro) aumentam a sua entrega ao trato vinícola.

Alguns destes oficiais de tanoaria envolveram-se mesmo no negócio da exportação sobretudo com destino à colónia do Brasil. Foram claramente os casos de Manuel de Almeida, morador na Rua de Baixo de Vila Nova ${ }^{2}$, José de Azevedo, morador ao adro da Igreja de Santa

\footnotetext{
${ }^{2}$ AHMP, L. 1370, Imposição do Vinho, fls. 52 v.
} 
Marinha, em Vila Nova ${ }^{3}$, Manuel Francisco da Costa, morador na mesma rua, Juiz do ofício de tanoeiro e oficial da pareação das pipas ${ }^{4}$.

Outros, como Domingos da Costa, igualmente Juiz do Ofício de tanoaria, morador na Volta de Vila Nova ${ }^{5}$ venderam sobretudo no mercado local e na área circundante da cidade do Porto designada por Termo Velho, que engloba Gaia e Matosinhos.

Também houve alguns destes tanoeiros a apostar nos mercados do norte da Europa. Foi claramente o caso de Domingos da Costa ${ }^{6}$.

O mestre tanoeiro António da Costa, da Porta Nova funcionou sobretudo como comissário de produtores da região do Douro que lhe confiavam o trato dos seus vinhos ${ }^{7}$.

Manuel de Pinho, de Miragaia ${ }^{8}$, merece atenção particular. Tratou-se por certo de um dos mais importantes mercadores de vinho do seu tempo na freguesia de Miragaia, por isso foi eleito mordomo para as festas do Espírito Santo em 16 de Maio de 1723, para servir até $1724^{9}$, sinal do seu prestígio na comunidade ribeirinha do Porto. Manifestou em média, nos 30 anos da sua atividade 351,8 pipas de vinho. Não se limitou a vender vinhos na cidade do Porto, mas a sua atividade estendeu-se também à exportação para o Brasil e para o norte da Europa, para onde enviou em média anual 76,7 e 52,8 pipas, respetivamente. Embora sem grande expressão no cômputo dos seus manifestos, também vendeu algum vinho para os arredores do Porto, nomeadamente para Matosinhos e São João da Foz. O mercado da capital também o interessou. Vendeu vinhos verdes e maduros. Os maduros do Douro constituíram a parte mais significativa dos vinhos que fez entrar na cidade, embora tenha negociado com vinhos de Viana.

\section{Vidros e garrafas}

Nos séculos XIV e XV a garrafa era em ferro, revestida a couro e destinava-se sobretudo a transportar o vinho próprio do viajante. Posteriormente e pouco a pouco, começou a utilizar-se o vidro insuflado. Até ao século XVI, este objeto era considerado precioso. Contudo, entre os séculos XVII e primeira metade do XVIII, a garrafa não se destinava ainda à conservação do vinho. Somente em meados do XVIII as garrafas começam a chegar às mesas (ARTS ET MÉTTIERS DU VIN, s. d., p. 77).

No que se refere ao Vinho do Porto ou vinho do Douro, os testemunhos mais antigos do uso de garrafas são de origem arqueológica e remontam aos séculos XVII e XVIII. Foram encontrados nas escavações realizadas na "Casa do Infante", ou seja no espaço da antiga alfândega da cidade,

\footnotetext{
${ }^{3}$ AHMP, L. 1370, Imposição do Vinho, fls. 36-39.

${ }_{5}^{4}$ AHMP, L. 81, Vereações, fls. 345-346.

${ }^{5}$ Até 1722 declarou-se morador de fora da Porta Nova à fonte do Touro. AHMP, L. 1324, Imposição do Vinho, fls. 273. A partir daquele ano transferiu as suas instalações para Vila Nova. AHMP, L. 1338, Imposição do Vinho, fls. 97.

${ }^{6}$ AHMP, L. 1357, Imposição do Vinho, fls. 193 e AHMP, L. 1359, Imposição do Vinho, fls. 211.

7 AHMP, L. 1319 a 1341 , Imposição do Vinho.

${ }^{8}$ AHMP, L. 1332, Imposição do Vinho, fls. 147.

${ }_{9}$ APM, Livro das eleições dos mordomos, fls. 13 v.
} 
mandada erigir pelo rei D. Afonso IV em 1354 (TAVARES, Rui, 1990, p. 40), ainda hoje um espaço nobre e preservado do Porto. Implantada na área mais antiga da velha urbe medieva hoje património da humanidade, o edifício actual que integra estruturas primitivas da alfândega régia foi classificado monumento nacional em 1924. Contudo, somente a partir de 1991 lá se iniciaram escavações de algum significado. Foram esses trabalhos que permitiram o reconhecimento de uma longa sequência ocupacional da época romana aos nossos dias. Nessa prospeção, foram encontrados sobrepostos a vestígios de construções tardo-romanas, níveis do período compreendido entre os séculos XIV e XVI que revelaram uma intensa ocupação humana do local, decorrente da atividade das "casas da alfândega", do próprio edifício aduaneiro e da Casa da Moeda.

Foi precisamente nesses estratos que foram encontrados fragmentos de garrafas de vidro provenientes de depósitos dos séculos XVII e XVIII e alguns do século XIX.

Do vasto espólio recolhido relacionado com o acondicionamento vinário destacamos:

- Fragmentos de ânforas tardo-romanas;

- Pichees Bragueeses - cerâmica de paredes finas (2mm) - louça muito comercializada pela cidade do Porto a avaliar pelos registos alfandegários;

- Um Belarmino do século XVI, certamente proveniente dos contactos exteriores da cidade com Hamburgo - São peças de cerâmica cozidas a altas temperaturas, totalmente vitrificadas, em forma de jarros ou garrafas decoradas com uma máscara barbada.

- Uma garrafa proveniente das Torres, datável do século XVII - Shaft \& Globe;

- Encontrou-se ainda uma garrafa Squat Cylinder, datada de 1740-1750 (COSME, Susana Rodrigues, 2001, p. 193-201).

Não se sabe muito quanto à origem destas garrafas. Portugal nos séculos XVII e XVIII conheceu um único forno para produzir garrafas, o forno do Covo, isto a norte do Tejo. Só a partir de 1748, com o estabelecimento do inglês John Beare na Marinha Grande se começa a esboçar o arranque da indústria do vidro que $\mathrm{D}$. João $\mathrm{V}$ protegeu através da transferência para o mesmo local da Real Fábrica do Vidro antes estabelecida em Coina. De resto, nesta localidade, é conhecida a indústria vidreira desde o século XV. Nas fábricas aí instaladas, não se encontra documentada a produção de garrafas. Acredita-se que é provável que já as produzissem mas em número pouco relevante. Contudo, parece-nos que as garrafas destinadas ao armazenamento de vinho, no caso do Porto, tenham tido origem na importação de Inglaterra, onde a sua produção é conhecida pelo menos desde 1640. De resto, nas mercadorias de importação entradas pela barra do Douro em navios ingleses ou oriundos de portos britânicos com destino a mercadores ingleses residentes no porto, são feitas referências a "vidros" sem se especificar de que vidros se tratam. Serão garrafas? A pergunta é legítima e é bem provável que o sejam, já que os ingleses do Porto as importaram, como importaram outro tipo de vasilhame (CARDOSO, António Barros, 2003, Vol. II, p. 893-908). 


\section{As garrafas e o Porto Vintage}

Como todos sabemos, "Vintage" significa vindima. Para os ingleses do Porto, como já referimos, os grandes comerciantes de vinho no século XVIII, o termo passou a ter outro significado. "Vintage" passa a significar não uma vindima qualquer, mas a vindima de um ano excecional. Trata-se de um ano de produção de um vinho do Douro retinto, encorpado, com paladar e aroma muito finos, frutado e forte, digno de ficar na memória e na garrafeira. Ou seja, um vinho para durar, engarrafado jovem e com capacidade de envelhecer sem perder todas as suas qualidades (PEREIRA, Gaspar Martins, 1999, p. 13).

A designação é britânica mas, até meados do século XIX, estes vinhos a envelhecer em garrafas de vidro eram designados por "vinhos de novidade". A adoção da designação "vintage" como indicadora de um vinho do Porto de qualidade superior, só foi pela primeira vez aceite em 1932 pela Comissão de Viticultura do Douro (PEREIRA, Gaspar Martins - Origem e evolução de um grande vinho: in "Porto Vintage", Porto, IVDP - Campo das Letras - Editores, S.A., 1999, p. 15), vinhos estes que passaram a poder ser exportados para a Inglaterra com pelo menos 18 meses de idade. Contudo, até aos anos sessenta do século passado, perdurou a já referida expressão "Vinhos de Novidade". Por exemplo, no Solar do Vinho do Porto, sala de provas por excelência dos melhores néctares do Douro, a expressão foi usada até essa data.

Mas quando nasceram estes vinhos? O nascimento do Porto Vintage não pode ser dissociado das notícias mais recuadas sobre vinhos produzidos na região do Douro e que em 1531-1532, Rui Fernandes refere como vinhos com a capacidade de envelhecerem sem dano e que os havia de 4,5e 6 anos e de quantos mais anos mais excelentes e mais cheirosos eram (FERNANDES, Rui, p. 546613). Estes vinhos diferenciavam-se dos restantes produzidos na região do Douro que ainda hoje os designa por "vinhos finos" que os ingleses aguardentaram a partir da segunda metade de setecentos.

$\mathrm{O}$ incremento comercial inglês a partir da segunda metade do século XVII e particularmente na segunda metade do XVIII protagonizados pelos mercadores ingleses instalados na cidade do Porto, conduziram à aguardentação dos vinhos do Douro para a sua melhor conservação e transporte e foi na sequência deste processo de apuro das diversas qualidades de vinhos do Porto que surgiram já na segunda metade do século XVIII os "vintage" vinhos que o consumidor mais exigente guardou não só na memória mas também na garrafeira. Ora, tratando-se de um vinho que engarrafado jovem que necessita de envelhecer lentamente, durante dez, vinte ou mais anos para atingir o pleno das suas qualidades, as velhas garrafas de corpo bojudo ou irregular e gargalo comprido, do tipo "shaft \& globe", "onion", "bladder" e "mallet", anteriores a meados do século XVIII, adequavam-se muito mal à função de guarda do vinho, antes serviam de vasilha de transporte da pipa à mesa do consumidor. Algumas, como a imagem documenta tinham a marca ou do fabricante, ou do proprietário que as usou.

Warner Allen (WARNER, H. Walter - The Wines of Portugal. In SIMON, André L., 1962, p. 433) refere que o aparecimento do atual tipo de garrafa de vinho do Porto, caracterizada pelo alongamento do corpo cilíndrico e encurtamento do gargalo, terá aparecido por volta de 1775, altura em que para este autor admite o aparecimento do primeiro "vintage port". Contudo, um catálogo da Christie's de 
1768 anuncia já a venda de um "vintage" de 1765 (PEREIRA, Gaspar Martins, 1999, p. 22). Ou seja, os melhores vinhos do Douro acompanharam o processo de vinificação em garrafa que outras regiões vitícolas estavam simultaneamente a desenvolver: Bordéus - Michael Broadbent, refere um claret de 1771 com o primeiro "vintage" bordalês, vendido num leilão da Christie's de 1776. Duas das mais antigas garrafas a conservar o vinho de Bordéus datam de 1784 - um Château Margaux e um Château d'Yquem e há mesmo a notícia de que um grupo de enófilos terá aberto, em 1987, uma garrafa deste último, mas datada de 1747 (PEREIRA, Gaspar Martins - Origem e evolução de um grande vinho: in "Porto Vintage", Porto, IVDP - Campo das Letras - Editores, S.A., 1999, p. 23 (PEREIRA, Gaspar Martins, 1999, p. 24).

No Porto, através dos tratados sobre vinhos de finais do século XVIII e inícios do século XIX, sabemos que a prática do envelhecimento em garrafa era utilizada desde há décadas. No fim do século XIX, a Real Companhia Vinícola do Norte de Portugal, ao anunciar a venda de vinhos de uma frasqueira reservada, dá notícia de vinhos de 1756, 1760 e 1790 a preços que variaram entre os 20 e os 10 mil réis a garrafa.

Do que não há dúvidas é que os "Vintage port" estão intimamente ligados à garrafa que os guarda no tempo e às transformações no seu formato. Era impossível acomodar os vinhos como a imagem documenta, usando as garrafas em formato de cebola.

\section{A terminar}

Refira-se que os estudos sobre a evolução histórica do vasilhame que guardou ao longo dos séculos os vinhos do Douro que acabaram por correr mundo sob a designação Porto, estão ainda em estado embrionário. Contudo, no que se refere às caves é possível adiantar datas e motivos para o seu aparecimento em Vila Nova, com intensidade a partir dos anos quarenta do século XVIII. Faltamnos estudos sobre a evolução da sua arquitetura e os sequentes estudos comparativos com a evolução arquitetónicas dos locais de armazenamento de outras regiões vitícolas europeias igualmente importantes no contexto da viticultura mundial. Quanto à tanoaria portuense, vimo-lo, a sua importância aparece documentada desde tempos medievos. Algumas notícias esparsas falam de evolução no século XVIII, face à influência inglesa. Do protagonismo dos oficiais tanoeiros no negócio do vinho do Porto, temos notícias que remontam aos alvores de setecentos. Sabemos alguma coisa sobre a relação entre os Porto "vintage" e a evolução das garrafas no mercado portuense. Fica a certeza que o Porto acompanhou a moda de envelhecer os seus melhores vinhos em garrafeiras, como sucedeu com outros grandes vinhos do mundo ao longo da segunda metade do século XVIII. 


\section{Fontes}

AHMP, L. 2090, Registo Geral

AHMP, L. 1370, Imposição do Vinho

AHMP, L. 1324, Imposição do Vinho

AHMP, L. 81, Vereações

AHMP, L. 1357, Imposição do Vinho, fls. 193 e AHMP, L. 1359, Imposição do Vinho, fls. 211.

AHMP, L. 1319 a 1341, Imposição do Vinho.

AHMP, L. 1332, Imposição do Vinho.

APM, Livro das eleições dos mordomos

\section{Bibliografia}

LIMA, Eng. J. da Costa, Porque é que os armazéns de vinho do Pôrto se encontram em Gaia? in "O Tripeiro", Série V, Ano I, fasc. 3, Porto, 1945.

CRUZ, António - Os Mesteres do Porto: Porto, 1943.

MACAHDO, Maria de Fátima Pereira - O Porto de D. Manuel I a D. João III (1518-1530): Porto, Faculdade de Letras, 1997, p. 109 (edição policopiada).

GUIMARÃES, Gonçalves - A Oficina de Tanoaria de Miguel dos Santos Oliveira: Vila Nova de Gaia, Câmara Municipal de Vila Nova de Gaia, 1998.

SILVA, Francisco Ribeiro da - O Porto e o seu Termo - Os Homens, as Instituições e o Poder, Porto: AHMP, 1988, Vol. I e II.

CARDOSO, António Barros - Baco \& Hermes - O Comércio Interno e Externo dos Vinhos do Douro: Porto - GEHVID - Grupo de Estudos de História da Viticultura Duriense e do Vinho do Porto, 2003, Vol. I e II.

ARTS ET MÉTTIERS DU VIN - edition du Musée Vaudois de la Vigne et du Vin, s. d.

TAVARES, Rui - Do Almazem Régio à Alfândega Nova: Evolução de um tipo de arquitectura portuária. In "A Alfândega Régia e o despacho Aduaneiro": Porto, Câmara Municipal do Porto, 1990.

COSME, Susana Rodrigues - Garrafas da Época Moderna na Casa do Infante. In "Actas del Simpósio de La Associación Internacional de Historia y Civilización de La Vid y el Vino", Puerto de Santa Maria, 2001, Vol. I.

PEREIRA, Gaspar Martins - Origem e evolução de um grande vinho: in "Porto Vintage", Porto, IVDP - Campo das Letras - Editores, S.A., 1999.

FERNANDES, Rui - Descripção da cidade de Lamego duas léguas (1532). In "Inéditos de História Portuguesa. Tomo V. Lisboa: Academia Real das Ciências, 182.

WARNER, H. Walter - The Wines of Portugal. In SIMON, André L. (ed.) - "Wines of the World", Londres, 1962.

PEREIRA, Gaspar Martins - Origem e evolução de um grande vinho: in " Porto Vintage", Porto, IVDP - Campo das Letras - Editores, S.A., 1999. 